\title{
Comprehensive Management Model for Solid Waste Collection and Transportation in Peruvian Urban Municipalities
}

\author{
Renato Bernal ${ }^{1}$, Edgar Sánchez ${ }^{1 *}$, David Mauricio ${ }^{2}$ and Carlos Raymundo ${ }^{2}$ \\ ${ }^{1}$ Escuela de Ingeniería de Gestión Empresarial, Universidad Peruana de Ciencias Aplicadas (UPC), Lima, Perú \\ ${ }^{2}$ Dirección de Investigación, Universidad Peruana de Ciencias Aplicadas (UPC), Lima, Perú \\ *Corresponding Author: Edgar Sánchez, Escuela de Ingeniería de Gestión Empresarial, Universidad Peruana de Ciencias Aplicadas \\ (UPC), Lima, Perú.
}

Received: August 07, 2019; Published: September 09, 2019

DOI: $10.31080 / A S A G .2019 .03 .0644$

\begin{abstract}
Herein, comprehensive management model of municipal solid waste collection and transportation, "MIGRU", is proposed, based on the Lean Six Sigma, VSM, and Servqual methods. This model considers and includes three important management systems for an efficient collection value chain: quality management, route management, and HR and community management. The proposed model was implemented and validated in the municipality of Lima, Peru, and the results showed that municipal costs were reduced up to $40 \%$, solid waste was reduced in the streets, and routes and processes were updated and improved in addition to an improvement in the participation and environmental education of citizens. Thus, correct management of the proposed model's three general approaches to a very positive municipal impact at economic and environmental levels, without the investment of excessive amounts of money observed in first-world countries.
\end{abstract}

Keywords: Waste Management; Municipal Solid Waste; Waste Collection; Municipal Management; Municipal HR

\section{Introduction}

One of the biggest economic and social problems affecting Latin American countries is the poor management of municipal solid waste [1]. The main causes of this problem are a lack of fixed routes through the municipalities, little capacity of administrative personnel, and the limited revenue of municipalities. The defective management of municipal solid waste (MSW) is an economic and administrative problem that municipalities have thus far failed to solve in the short term as well as the long term. To solve this problem, currently, in cities of developed countries, successful international models have been implemented, leading to $\sim 90 \%$ reduction in the use of landfills and environmental pollution through the elimination or recycling of MSW. One such MSW main management model is the "waste to energy" (WTE) model. According to the Confederation of European Waste-to-Energy Plants (CEWEP), the WTE model includes incinerating MSW that could not be prevented or recycled at WTE plants to generate energy [2]. However, a significant challenge to the successful implementation of a WTE plant is the initial large investment required to conduct the project in addition to the annual budget required to maintain operations in the plant. According to an Estonian construction company called Waste to Energy International, the investment required for a plant with a capacity to convert 40,000 tons of solid waste per year is $41,000,000$ million dollars [2].

Hence, this research aims to optimize the MSW collection model using hard engineering tools and methodologies to reduce operating costs, maximize staff productivity, and raise awareness among the population regarding SW collection based on the service quality requirements.

\section{State of the Art}

Source separation programs are also available as mentioned in [3], with a total of $40 \%$ residents willing to collaborate and continue with the recycling model. Another tool is QFD, which is explained in article [4]. A survey was conducted in [4] with a population sample of 324 farmers in 16 common parks, in Moroleón, Guanajuato, to find the customer requirements and priorities for further analysis.

Finally, simulation models exist for the collection route system. In [5], the authors explain the need for an optimal solid waste collection model to improve the quality of life, economic aspects, and environmental issues in different municipalities, this is why they propose a vehicle routing model that includes multiple transfer stations, collection sites, and non-homogeneous vehicles. However, in [6], the authors discuss an optimized route plan in a static context, following which a dynamic context modeled by a multi-agent system is integrated. This study, conducted in the city of Hagiang, reduced collection costs by $11.3 \%$. Another alternative is presented in [7], wherein the authors define a mathematical model that determines the minimum distant route between the different collection points. Then, a heuristic method is applied to determine the optimum minimum number of vehicles to be used and the optimum distance to collect waste. 


\section{Proposed model}

In the present research, a comprehensive model of urban MSW collection and transport management is proposed. Herein, the acronym MIGRU will be used for the proposed model. The objective of MIGRU is to support the municipal process to collect and transport domestic waste with greater efficiency and productivity, create economic value, maximize the organizational culture of the municipality, and generate an effective social culture with respect to MSW in society. The proposed model is based on Lean Six Sigma, VSM, and Servqual tools and focuses on three areas of management: service quality, route, and community culture management together with HR. Figure 1 outlines the proposed model.

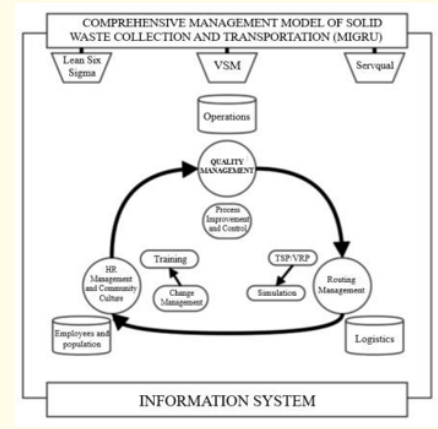

Figure 1: Proposed Model
First, MIGRU measures and analyzes the quality of service at an operational level by applying Six Sigma, VSM, and Lean Service engineering tools. Second, MIGRU considers that for route improvements, the SDVRP model must be applied by dividing the study district into quadrants. Then, the ARENA simulator is used to verify and measure different results and find the optimal economic and cultural level. Finally, MIGRU applies change management and stakeholder management methodologies to ensure an effective MSW culture.

The novelty of the proposed model is reflected in the combination and integration of the three managements tools used herein that are based on Lean Six Sigma, VSM, and Servqual methodologies.

Next, we present the summary of activities and main processes of the MIGRU model (Table 1 ).

\section{Validation}

The validation of the proposed model is explained step by step, below.

\section{Measure}

Measure quality management

Information on the following points was gathered.

\begin{tabular}{|c|c|c|c|}
\hline $\begin{array}{l}\text { Management } \\
\text { stages/types }\end{array}$ & Quality management & Route management & $\begin{array}{c}\text { HR and community man- } \\
\text { agement }\end{array}$ \\
\hline $\begin{array}{l}\text { Definition/ } \\
\text { Redefinition }\end{array}$ & $\begin{array}{l}\text { Establishing objectives of service quality } \\
\text { Update organization and operation manual } \\
\text { Define recruiting and personnel selection } \\
\text { processes } \\
\text { Implement project directory and work teams }\end{array}$ & $\begin{array}{l}\text { Define objectives and indicators of } \\
\text { route management } \\
\text { Define the organization and operation } \\
\text { manual (MOP) for route management } \\
\text { Information compilation } \\
\text { Structuring of the service's situational } \\
\text { state } \\
\text { Updating of policies and occupational } \\
\text { safety and health manual } \\
\text { Updating the district's street maps } \\
\text { Updating heat maps and solid waste } \\
\text { collection points } \\
\text { Updating and improving water collec- } \\
\text { tion routes }\end{array}$ & $\begin{array}{l}\text { Definition of objectives of } \\
\text { HR and community culture } \\
\text { management } \\
\text { Definition of the organization } \\
\text { and operation manual (MOP) } \\
\text { of route management } \\
\text { Definition of change needs } \\
\text { Situational analysis and } \\
\text { identification of important } \\
\text { individuals and processes of } \\
\text { the service }\end{array}$ \\
\hline Planning & $\begin{array}{l}\text { Information compilation } \\
\text { Structuring of the service's situational state } \\
\text { Definition of initial VSM processes and } \\
\text { structures } \\
\text { Valuing of municipal service processes } \\
\text { Measurement and classification of the main } \\
\text { problems } \\
\text { Drawing up an improvement plan with a } \\
\text { schedule } \\
\text { Drawing up a financial plan } \\
\text { Drawing up a mitigation and contingency } \\
\text { plan } \\
\text { Presentation and approval of plans of the } \\
\text { first instance to authorities } \\
\text { Formal approval and documentation sent to } \\
\text { parties }\end{array}$ & $\begin{array}{l}\text { Analysis and measurement of indus- } \\
\text { trial losses based on six losses of lean } \\
\text { manufacturing } \\
\text { Redesigning the operations plan } \\
\text { Redesigning and implementation of } \\
\text { the communication plan } \\
\text { Analysis and research of new solutions } \\
\text { and optimal routing methods } \\
\text { Selection of the optimal routing } \\
\text { method Drawing up of weight and } \\
\text { node distance matrix }\end{array}$ & $\begin{array}{l}\text { Stage planning } \\
\text { Leadership plan design } \\
\text { Communication plan design } \\
\text { Training plan design } \\
\text { Motivation design plan }\end{array}$ \\
\hline
\end{tabular}




\begin{tabular}{|c|c|c|c|}
\hline $\begin{array}{l}\text { Execution } \\
\text { and Follow- } \\
\text { up }\end{array}$ & $\begin{array}{l}\text { Implementation of indicators } \\
\text { Follow-up and meetings before important } \\
\text { events or incidents } \\
\text { Implementation of tactics and contingencies }\end{array}$ & $\begin{array}{l}\text { Selection and execution of simulation } \\
\text { software and route generators }\end{array}$ & $\begin{array}{l}\text { Execute activities defined in } \\
\text { the plan } \\
\text { Execute training schedules } \\
\text { Hold meetings to clarify } \\
\text { doubts } \\
\text { Evaluate personnel } \\
\text { Hold meetings to follow-up } \\
\text { on changes Evaluate the } \\
\text { team's performance with } \\
\text { new processes } \\
\text { Keep the team informed on } \\
\text { any unplanned issue }\end{array}$ \\
\hline Evaluation & $\begin{array}{l}\text { Controls and periodic revisions } \\
\text { Implementation of controls and periodic } \\
\text { revisions } \\
\text { Self-questioning } \\
\text { Control and evaluation of process and final } \\
\text { services }\end{array}$ & $\begin{array}{l}\text { Evaluation of different scenarios of } \\
\text { optimal routes } \\
\text { Verification and updation of the study } \\
\text { field Printed or digital documents of } \\
\text { the routing process } \\
\text { Report and documents of incidents }\end{array}$ & $\begin{array}{l}\text { Evaluation activities are } \\
\text { undertaken } \\
\text { Establish new objectives and } \\
\text { goals } \\
\text { Define reinforcement actions } \\
\text { Create plans to replace } \\
\text { current change leaders } \\
\text { Gradually dismantle existing } \\
\text { incentives }\end{array}$ \\
\hline
\end{tabular}

Table 1: Summary of Activities and Main Processes of the MIGRU Model.

- Descriptive information on the last three months of VSM processes.

- Defects, overproduction, delays, unused talent, unnecessary transportation, unnecessary inventory, and transfers of each VSM process.

Next, we determined the sigma of the current solid waste collection management based on the losses calculated in the VSM analysis and in accordance with the Six Sigma protocols.

To measure the quality of the service offered, after formulating the questions and asking them, a quantification of the service offered by the municipality was obtained.

\section{Measure route management}

Through the collection of data and official reports, we observed that the municipality of the study has not measured or tried to improve its collection routes owing to political, economic, and other factors.

Measure HR management and community culture

The 360-degree feedback survey was conducted for three workers in the area of solid waste management of the municipality. All three workers held different positions (assistant manager, environmental technician, and chief operator).

\section{Improvements}

Improve quality management

The Servqual survey was conducted for the third time, after the implementation of changes in the solid waste management area. Notably, the surveys were conducted for different people within the area of the case study.

\section{Improve route management}

In this study, the proposed model was validated in the area of Lima called Mangomarca. Below, you will find the important points required to collect information and validate our optimal routing (Figure 2).

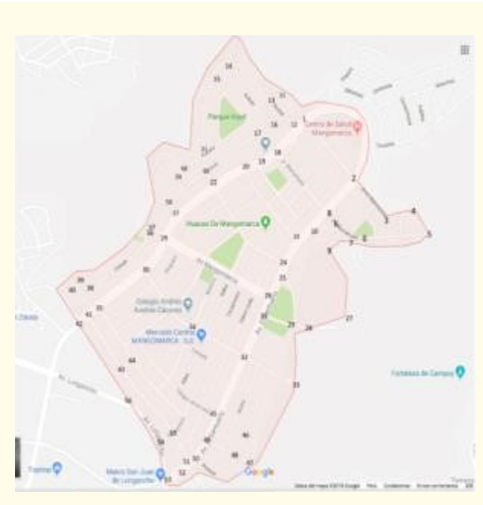

Figure 2: Distribution of nodes.

The node matrix of the different points of the segment to be studied was obtained, tests were performed using the optimal routing software. In this case, the free program TSP Solver and generator was used. The simulation software calculated $7442 \mathrm{~m}$ of the optimal route, but in a disorderly manner. The order of the route is based on distance and economic issues; accordingly, optimal final route was calculated (Figure 3 ).

Improve HR management and community culture

Management plans were formulated for both the staff and the population, as follows. Staff: Ongoing training for personnel, assign specific routes, Register and control collection trucks, draw up an incentive plan for good behavior, improve facilities for personnel 


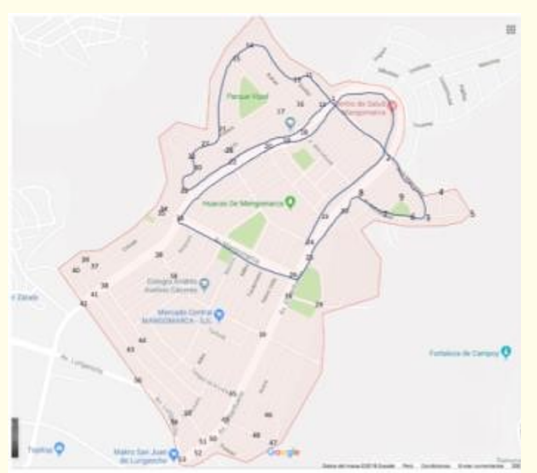

Figure 3: Final optimal route.

\section{Control}

Control quality management: Checks and periodic reviews, Implementation of controls, Self-questioning, Quality circles, Evaluation of the final processes and services.

Control route management: Verification and updates in the fields of study, Printed documentation, Incident report.

Control HR management and community culture.

\section{Results}

In the quality of service, according to Servqual, we see positive improvements in the five dimensions. Previously, three dimensions were negative and two dimensions had a very low value. The values of the gap are as follows: reliability decreases from a gap of 1.15 to 0.3 ; sensitivity increases from 0.1 to 0.65 ; security increases from -0.43 to 0.43 ; empathy increases from -0.45 to 0.18 ; and tangible elements increase from 0.1 to 0.33 .

In terms of routing, before the tests, the vehicles traversed all streets, thus wasting time and consuming considerable resources. However, with the new optimal route, both time and costs can be reduced. However, this would not be useful if good change management is not applied at both the HR and operational levels.

\begin{tabular}{|l|c|c|c|}
\hline \multicolumn{1}{|c|}{ Result 1 } & $\begin{array}{c}\text { Quantity } \\
\text { in meters }\end{array}$ & Result 2 & $\begin{array}{c}\text { Annual costs } \\
\text { in soles }\end{array}$ \\
\hline Initial route & 3349 & $\begin{array}{c}\text { Initial and } \\
\text { traditional route }\end{array}$ & $22,000,000$ \\
\hline $\begin{array}{l}\text { Route with } \\
\text { MIGRU }\end{array}$ & 1600 & Rate of reduction & $47 \%$ \\
\hline $\begin{array}{l}\text { Rate of } \\
\text { reduction }\end{array}$ & $47 \%$ & $\begin{array}{c}\text { Possible cost } \\
\text { with MIGRU }\end{array}$ & $10,340,000$ \\
\hline
\end{tabular}

Table 2: Results of route management.

Three scenarios were simulated herein and the results were positive, achieving a reduction of up to $47 \%$ in costs. As for HR management and community culture:
- $100 \%$ approval of the team was achieved regarding the need for change.

- $\quad$ The population understood the issue and was willing to be trained by municipal employees.

- $100 \%$ employees attended the training and motivation talks.

- The staff management plan was executed without any issues.

- The population management plan was implemented with great approval.

- No adverse incident occurred during the implementation of the change management program in the municipality.

\section{Conclusion}

A comprehensive management model for SW collection was designed in this work to improve the quality of service, reduce operating costs, maximize staff productivity, and raise awareness among the population regarding SW collection on the basis of service quality requirements.

- $\quad$ A literature review was conducted to identify existing management models of solid waste collection to create an innovative model for solid waste management.

- The quantitative and qualitative situation of the management of current MSW collection was identified and post implementation of the new model, processes, service times, and costs of solid waste collection management were determined.

- The quality level of the collection service was quantified before and after the implementation to know the client's requirements.

- A new solid waste collection route was proposed to increase collection coverage and reduce operating costs.

- The change management plan in the operational area was proposed based on the optimal routes calculated to achieve a commitment to the new solid waste management model.

- A training and conference plan was proposed to local residents to raise their awareness regarding solid waste issues.

\section{Bibliography}

1. M d Ambiente. "Plan nacional de gestión integral de resiudos sólidos" (2016).

2. CEWEP. What is Waste-to-Energy (2018).

3. P S and A Sharp. "A system dynamics model to evaluate effects of source separation of municipal solid waste management: A case of Bangkok, Thailand". Waste Management 52(2016): 50-61.

4. Narda B Ocampo Jimenez and Roberto Baeza Serrato. "Effectiveness of QFD in a municipal administration process". Business Process Management Journal 22.5 (2016): 979-992. 
5. Louati A and L Son. "Modeling municipal solid waste collection: A generalized vehicle routing model with multiple transfer stations, gather sites and inhomogeneous vehicles in time windows". Waste Management 52 (2016): 34-49.

6. Khanh Nguyen-Trong., et al. "Optimization of municipal solid waste transportation by integrating GIS analysis, equationbased, and agent-based model". Waste Management 59 (2017): 14-22.

7. Shan-Huen Huang., et al. "Vehicle routing-scheduling for municipal waste collection system under the "Keep Trash off the Ground" policy"'. Omega 55 (2015):24-37.

Volume 3 Issue 10 October 2019

(C) All rights are reserved by Edgar Sánchez., et al. 